\title{
Quality of life after first-ever stroke: An interview- based study from Blantyre, Malawi
}

\section{T Heikinheimo ${ }^{1,2}$, D Chimbayo ${ }^{2}$}

1. Department of Neurology, Helsinki University Central Hospital, Helsinki, Finland

2. Department of Medicine, College of Medicine, University of Malawi, Blantyre, Malawi

Correspondence to: Dr. Terttu Heikinheimo

Email: terttu.heikinheimo-connell@hus.fi

\section{Abstract}

\section{Background}

In post-stroke patients, impairment of quality of life (QOL) has been associated with functional impairment, age, anxiety, depression, and fatigue. Good social support, higher education, and better socioeconomic status are associated with better QOL among stroke survivors. In Africa studies from Nigeria and Tanzania have reported on post-stroke QOL.

\section{Aim}

The aim of this study was to describe QOL more than six months after first-ever stroke in Malawi.

\section{Methods}

This was an interview-based study about a stroke-surviving cohort. Adult patients were interviewed six or twelve months after their first ever stroke. HIV status, modified stroke severity scale (mNIHSS) score, and brain scan results were recorded during the acute phase of stroke. At the time of the interviews, the modified Rankin scale (mRS) was used to assess functional outcome. The interviews applied the Newcastle Stroke-specific Quality of Life Measure (NEWSQOL). All the data were analysed using Statview ${ }^{\text {TM }}$ the $\mathrm{X}^{2}$ test compared proportions, Student's t-test compared means for normally distributed data, and the Kruskal-Wallis test was used for nonparametric data.

\section{Results}

Eighty-one patients were followed up at least six months after the acute stroke. Twenty-five stroke patients (ten women) were interviewed with the NEWSQOL questionnaire. Good functional outcome (lower mRS score) was positively associated with better QOL in the domains of activities of daily living (ADL)/self-care $(\mathrm{p}=0.0024)$ and communication $(\mathrm{p}=0.031)$. Women scored worse in the fatigue $(\mathrm{p}=0.0081)$ and cognition $(\mathrm{p}=0.048)$ domains. Older age was associated with worse QOL in the ADL ( $\mathrm{p}=$ 0.0122 ) domain. Seven patients were HIV-seroreactive. HIV infection did not affect post-stroke QOL.

\section{Conclusion}

In Malawi, within specific domains, QOL after stroke appeared to be related to patients' age, sex, and functional recovery in this small sample of patients.

\section{Introduction}

The term quality of life (QOL) is widely used to evaluate a person's general wellbeing. There is broad consensus that QOL should include physical, psychological, functional, and social aspects. In the medical world, we concentrate on health-related quality of life ${ }^{1}$.

In high-income countries, studies of QOL after stroke have established that higher QOL is associated with independent daily living, higher education, better socioeconomic status, and better social support ${ }^{2-6}$. Lower QOL has been associated with anxiety, depression, and fatigue ${ }^{5,7,8}$.

In Africa, the social, psychological, and medical contexts differ from those in Western countries. In Sub-Saharan African (SSA) countries hit hard by the HIV epidemic, QOL has been assessed in HIV-affected populations ${ }^{9,10}$. In one study from Malawi, HIV-seropositive people (267) were compared to HIV-seronegative people (598) with the use of the Short Form 36 Health Survey (SF-36) to analyse QOL ${ }^{10}$. This study concluded that HIV infection, the severity of HIV-related symptoms, and CD4 count less than 200 cells/ $\mathrm{mm}^{3}$ are associated with lower QOL. In the five African countries of Lesotho, Malawi, South Africa, Swaziland, and Tanzania, a longitudinal study analysed HIV-related stigma and QOL'. The results were parallel to those in Western countries: while stigma continues to have a negative impact, other factors, like taking antiretroviral drugs, can improve life satisfaction and QOL. The determinants of QOL after stroke, however, may be different.

Some studies have described post-stroke QOL in SubSaharan Africa ${ }^{11-14}$. Studies from Nigeria concluded that determinants of health-related QOL in stroke patients are stroke severity, functional recovery, laughter, and frequency of negative feelings or depression ${ }^{13,15}$. A study of 100 stroke patients and 100 apparently healthy adults in Nigeria and Germany, more than a month after stroke, divided QOL into physical and spiritual spheres ${ }^{14}$. Whereas the physical sphere-including sensory and motor function, mood, and interpersonal interactions-was sensitive to the negative impact of a stroke, the spiritual sphereincluding self-esteem, personal autonomy, and idealistic aspects of human life-remained stroke-resistant amongst the Nigerian participants. A Tanzanian study of 58 patients, one to five years after incident stroke, and 58 controls, found the strongest correlates with QOL after stroke were age, depression, anxiety, disability, motor function, and involvement in social events ${ }^{11}$. In a study from Kenya of young post-stroke patients, gender made a difference: men had better QOL than women ${ }^{12}$. Aetiology of stroke has not been found to impact QOL. We could not find any research about the impact of HIV on post-stroke patients in Africa.

Although some studies about the outcome of stroke have recently been undertaken in Malawi, the health-related QOL after stroke has not been investigated. This study aimed to follow-up and describe individual patients' reports about the impact of a first-ever acute stroke on their quality of life, some months after the stroke.

\section{Methods}

\section{Study context and setting}

This was a substudy of the Stroke Outcomes in Malawi (SOMA) study ${ }^{16}$, which was conducted by the Queen Elizabeth Central Hospital (QECH, Blantyre) medical department from August 2008 until April 2010. Patients were eligible for SOMA if they were aged 18 years or older and had a first-ever acute stroke within seven days before admission. SOMA participants were recruited from the admissions and medical wards of QECH. The SOMA study criteria excluded patients with previous stroke-like symptoms, head trauma, or other preceding central nervous system (CNS) diagnoses. Age, gender, civil status, and ability to speak English were recorded. SOMA recruited 147 acute stroke patients. Stroke severity was assessed at recruitment, and functional outcome and clinical subtype were also recorded. The presence or absence of HIV infection was determined using two standard rapid immunoassays (Uni-Gold ${ }^{\mathrm{TM}}$ Recombigen ${ }^{\circledR}$ HIV and http://dx.doi.org/10.4314/mmj.v27i2.4 
Determine ${ }^{\circledR}$ HIV-1/2). Computed tomography (CT) and magnetic resonance imaging (MRI) were used to differentiate haemorrhagic from ischaemic strokes. Patients without brain imaging were defined as having an undetermined stroke type. More detailed methods for case management, baseline assessment, and follow-up for the SOMA study are explained elsewhere ${ }^{16}$.

\section{Instrumentation}

The clinical subtype of stroke was recorded according to the Bamford classification ${ }^{17}$. This classification scheme divides people who have suffered a stroke into four different categories according to their presenting symptoms and signs. These categories are: total anterior circulation syndrome (TACS), partial anterior circulation syndrome (PACS), posterior circulation syndrome (POCS), and lacunar syndrome (LACS).

The National Institute of Health Stroke Scale (NIHSS) ${ }^{16,18}$ was used to assess stroke severity at the acute phase. The NIHSS was modified (mNIHSS) for the local setting: because people do not always know their age, the name of the current president of Malawi was asked instead. The mNIHSS is a two-minute test that quantifies the impairment caused by stroke. The test points scale is as follows: 0-6 is mild, $7-12$ is moderate, $13-20$ is severe, and $\geq 21$ is a very severe stroke.

The modified Rankin scale (mRS) estimates the functional outcome and measured disability after a stroke ${ }^{19}$. On the mRS, $0-2$ is considered a good outcome, 3 is fair, and 4-5 a poor outcome; $\mathrm{mRS} 6$ is defined as death ${ }^{19}$. In this study, the mRS scores were evaluated, for each participant, from the history before the onset of stroke and by the clinical findings at the time of recruitment.

The Newcastle Stroke-specific Quality of Life Measure (NEWSQOL) is a validated and reliable stroke-specific QOL measurement, with 11 domains and 56 items. The domains are: feelings, activities of daily living (ADL)/ self-care, cognition, mobility, emotion, sleep, interpersonal relationships, communication, pain/sensation, vision, and fatigue $^{20}$.

\section{Study procedures}

For this QOL study, all of the survivors from the SOMA study who had not absconded six months after the acute stroke were eligible. SOMA study participants were followed up at six to eight weeks, six months, and twelve months from stroke onset; QOL data were obtained at six and twelve months. At the follow-up visits, new health events, mRS scores, and the extent of patient mobility after the stroke were recorded. Whether or not each patient returned to work was also recorded. Where possible, a designated clinic at QECH arranged these appointments. For those patients who were unable to attend the follow-up visits, a home visit was arranged. NEWSQOL interviews were conducted once for each participant, during either the six-month or twelve-month follow-up visit ${ }^{20}$. The aim was to interview all patients at six months, but lack of an available Chichewaspeaking interviewer at certain times meant that some of the NEWSQOL interviews had to be done at twelve-month appointments. The study clinicians, DC (in Chichewa and/ or English, depending on participant preference) and TH (in English or with a translator), carried out the NEWSQOL as face-to-face interviews. A standard NEWSQOL interview takes 20-30 minutes to conduct, thus patients with severe expressive or receptive dysphasia and those who were severely ill or bed-ridden were not interviewed. To allow comparability to earlier studies, responses were similarly marked ${ }^{5,21}$. NEWSQOL item responses ranged from 1 (worst possible) to 4 (best possible). No score was recorded if a participant did not respond to a particular item, or if a participant was unaffected by the issue raised by a particular NEWSQOL item. The scores for each domain were calculated by summing $(=S)$ the corresponding item responses, and then applying the formula $(S-p) /(3 \times p) x$ 100 , where $\mathrm{p}$ is equal to the number of responded items in the domain, to give a score ranging from 0 (worst QOL) to 100 (best QOL). For our survey, the NEWSQOL script was translated into the local language, Chichewa, and the interviews were appropriately conducted either in English or Chichewa. All patients who fit the inclusion criteria agreed to participate in the QOL interviews.

\section{Ethics}

The University of Malawi College of Medicine Research and Ethics Committee granted approval for the study (COMREC P 07/07/573). Informed consent was obtained from able patients. Guardians provided consent for patients with reduced levels of consciousness or severe dysphasia.

\section{Statistical methods}

Data were analysed using Statview ${ }^{\mathrm{TM}}$. Descriptive statistics (mean, standard deviation [SD] or $95 \%$ confidence interval $[\mathrm{CI}]$ of the mean, and standard error of the mean [SEM]) were used to describe the baseline data. Proportions were compared using the $\mathrm{X}^{2}$ test and means using the Student's t-test, for normally distributed data, and the Kruskal-Wallis test for non-parametric data.

\section{Results}

Before follow-up at six months, 52 patients died and 14 absconded. This evaluation included the 81 remaining patients, of which $34(42 \%)$ were women (Table 1). No patient was disabled (mRS score 0-1) before the stroke. HIV infection was found in $26(32 \%)$ of the patients. WHO HIV stage on admission was I or II in 21 of the patients; 17 of these 21 participants had a CD4 count result recorded during the study, and 12 of them had a low count of $<300$ cells/ $\mathrm{mm}^{3}$. Low CD4 count and WHO stage III was found in four HIV-positive patients. Most of the patients ( $n=56$; $69 \%)$ were married, $12(15 \%)$ were widowed, and the rest were never married, separated, or divorced. The three most prevalent occupations were domestic work (16 patients), business (11), and small-scale farming (8). A minority had no employment (6) or were retired (7). More than one-third of the employed patients, $25(37 \%)$, returned to their previous occupations after the stroke; the majority $(68 \%)$ of these were men. Those who returned to work were slightly younger than the other patients $(47 \pm 15$ years), though the two eldest were female patients of 82 and 79 years of age. A few patients, $18(22 \%)$, changed residence following the stroke, primarily from urban to rural areas; all of these patients were severely disabled (mRS score 4-5) at the time of the acute stroke. After their initial discharge from hospital, 25 patients (31\%) received rehabilitation, most of them at the Kachere Rehabilitation Centre within Blantyre.

Of the 81 patients in this study, 25 participated in the NEWSQOL interview: 18 patients during the six-month visit and 7 patients during twelve-month visit. Of the excluded patients, 23 were dysphasic and four were severely ill. For 
Table 1. Demographics, stroke characteristics, and clinical outcomes of the study population

\begin{tabular}{|c|c|c|c|c|}
\hline & $\begin{array}{l}\text { All patients } \\
n=81\end{array}$ & $\begin{array}{l}\text { NEWSQOL } \\
\text { not done, } n=56\end{array}$ & NEWSQOL $n=25$ & p-value \\
\hline \multicolumn{5}{|l|}{ Demographics } \\
\hline Age, years mean $\pm S D$ & $54 \pm 16$ & $54 \pm 16$ & $54 \pm 15$ & 0.409 \\
\hline Gender, male & 47 & $32(57 \%)$ & $15(60 \%)$ & 0.406 \\
\hline Civil status/married & 56 & $38(68 \%)$ & $18(72 \%)$ & 0.357 \\
\hline HIVR & 26 & $19(34 \%)$ & $7(28 \%)$ & 0.357 \\
\hline \multicolumn{5}{|l|}{ Stroke characteristics } \\
\hline Ischaemic & 55 & $42(75 \%)$ & $13(52 \%)$ & 0.021 \\
\hline Haemorrhagic & 17 & $9(16 \%)$ & $8(32 \%)$ & 0.053 \\
\hline Unknown & 9 & $5(9 \%)$ & $4(16 \%)$ & 0.177 \\
\hline TACS & 2 & $2(4 \%)$ & $0(0 \%)$ & 0.172 \\
\hline PACS & 59 & $42(75 \%)$ & $17(68 \%)$ & 0.259 \\
\hline LACS & 12 & $6(11 \%)$ & $6(24 \%)$ & 0.062 \\
\hline POCS & 8 & $6(11 \%)$ & $2(8 \%)$ & 0.355 \\
\hline mNIHSS 0-6 & 23 & $11(20 \%)$ & $12(48 \%)$ & 0.004 \\
\hline mNIHSS 7-12 & 20 & $12(21 \%)$ & $8(32 \%)$ & 0.157 \\
\hline mNIHSS $13-20$ & 30 & $26(46 \%)$ & $4(16 \%)$ & 0.004 \\
\hline $\mathrm{mNIHSS}>20$ & 8 & $7(13 \%)$ & $1(4 \%)$ & 0.121 \\
\hline \multicolumn{5}{|l|}{ Clinical Outcome } \\
\hline mRS 0-2 & 49 & $29(52 \%)$ & $20(80 \%)$ & 0.008 \\
\hline $\mathrm{mRs} 3$ & 20 & $15(27 \%)$ & $5(20 \%)$ & 0.259 \\
\hline mRs 4-5 & 12 & $12(21 \%)$ & 0 & 0.006 \\
\hline back to work & 25 & $15(27 \%)$ & $10(40 \%)$ & 0.120 \\
\hline Moved & 16 & $13(23 \%)$ & $3(12 \%)$ & 0.123 \\
\hline
\end{tabular}

NEWSQOL = Newcastle Stroke-specific Quality of Life Measure, HIVR= HIV-seroreactive, TACS = total anterior circulation syndrome, PACS = Partial anterior circulation syndrome, LACS = lacunar syndrome, POCS $=$ Posterior circulation syndrome. $\mathrm{mNIHSS}=$ modified National Institution of Health Stroke Scale at baseline, $\mathrm{mRS}=$ modified Rankin Scale score at six months;

The two sub-groups are divided according to participation or non-participation in the NEWSQOL interview

15 patients who were unavailable for either an appointment or a home visit, a follow-up by telephone was conducted instead of the NEWSQOL interview. A Chichewa speaking interviewer or translator was unavailable for 14 patients.

The patients who completed the NEWSQOL interview had less severe strokes than those who did not complete it $48 \%$ versus $20 \%$, respectively, with mNIHSS 0-6 [ $\mathrm{X}^{2}$ for mNIHSS $0-6$ versus mNIHSS $\geq 7=6.84, \mathrm{p}=0.009])$. The patients who completed NEWSQOL also had better functional outcomes than those who did not $(80 \%$ versus $52 \%$, respectively, with mRS $0-2$ [X2 for mRS $0-2$ versus mRS $\geq$ $3=6.29, \mathrm{p}=0.012]$ ) (Table 1). Among the patients who suffered ischaemic strokes, a significantly smaller proportion was in the NEWSQOL group (52\% vs 75\%, p = 0.021).

The NEWSQOL scores and their relation to the patients' demographics and variables are shown in Table 2. Mean scores for all domains ranged from 70 to 86 (out of 100). Patients with worse functional outcomes (mRS scores) at six months scored significantly lower (worse QOL) in the domains of ADL/self-care $(95 \%$ CI of Pearson's correlation coefficient, $r$, was -0.793 to $-0.238, p=0.0024$ ), and communication $(95 \%$ CI of $\mathrm{r}=-0.707$ to $-0.0453, \mathrm{p}=$ 0.0307). Women scored significantly lower in the domains of cognition (women mean $67 \pm$ SEM 8.5 versus men mean $85 \pm$ SEM 4.4, $\mathrm{p}=0.0483$ ) and fatigue (women mean $63 \pm$ SEM 9.8 versus men mean $91 \pm$ SEM 2.9, $\mathrm{p}=0.0081)$. Older age was associated with worse QOL in the ADL domain
( $95 \%$ CI of $\mathrm{r}=-0.744$ to $-0.122, \mathrm{p}=0.0122$ ). The domains of sleep, relationships, vision, and pain were not significantly affected by any of the variables under investigation.

Stroke severity in the acute phase (mNIHSS), being married or living alone, returning to previous occupation, or having HIV infection did not significantly affect QOL in any of the domains.

\section{Discussion}

Our key findings were that, in some domains of NEWSQOL, poorer QOL after stroke was associated with female gender, a worse functional outcome, and older age. HIV infection did not worsen QOL, probably because HIV infection was more common in younger patients with milder stroke symptoms.

In the cognition and fatigue domains, females were found to have lower QOL scores. In many previous studies gender did not influence the QOL in stroke survivors ${ }^{8,13-15,22}$. European studies have found women having a better post-stroke QOL than men ${ }^{5,21}$. In other studies, however, including one from Kenya, women were found to have lower health-related QOL, as well as post-stroke QOL ${ }^{3,12,23,24}$. One confounder for the observations on gender and QOL may be depression, as post-stroke depression is more common in women ${ }^{8,24}$. Unfortunately, we did not assess our subjects for depression. Malawian women are generally less well educated than men, so stroke may increase the frustration related to gender-based educational differences ${ }^{25}$, though the level of education did not play a role in post-stroke QOL in a study from Nigeria ${ }^{15}$. Notably, in the SOMA study, women had poorer functional outcomes and were more disabled than men $^{16}$. An Italian study showed that women may have more limitations in muscle function and this affects the recovery from stroke ${ }^{26}$. As with our two eldest work returnees in this study, women in Malawi traditionally have more responsibilities than men at home and on the land and, moreover, act as the primary caregivers. Women may still be expected to perform household chores even after a stroke, and they may receive less care than men. Marital frustration and anxiety can emerge if a woman is unable to perform her duties with the same strength and endurance as before her stroke; this frustration and anxiety might also influence functional outcome. Marital status attenuated the gender difference in post-stroke QOL study in a recent study ${ }^{24}$.

The functional outcome was an important determinant of QOL in our study, particularly in the ADL/self-care and communication domains. A study from Tanzania also found that a worse QOL after stroke was associated with greater levels of physical disability, anxiety, depression, and reduced social interaction ${ }^{11,14}$. More than half of our participants had a severe index stroke (mNIHSS $\geq 13$ ).

Patients with milder strokes might not seek help, or are treated as outpatients in Malawi. Patients with the severest strokes have subsequent decreased autonomy, are more dependent on their caregivers, and thus have poorer QOL scores ${ }^{27}$. In the Malawian setting, patients with severe symptoms tend 
Table 2. The NEWSQOL domains and the variables of the interviewed patients

\begin{tabular}{|c|c|c|c|c|c|c|c|c|c|c|c|}
\hline Domain (items) & $\begin{array}{l}\text { Feelings } \\
\text { (6) }\end{array}$ & ADL (8) & $\begin{array}{l}\text { Cognition } \\
\text { (5) }\end{array}$ & $\begin{array}{l}\text { Mobility } \\
\text { (9) }\end{array}$ & $\begin{array}{l}\text { Emotions } \\
\text { (4) }\end{array}$ & $\begin{array}{l}\text { Sleep } \\
(6)\end{array}$ & $\begin{array}{l}\text { Relation- } \\
\text { ships (6) }\end{array}$ & $\begin{array}{l}\text { Commu- } \\
\text { nication } \\
\text { (4) }\end{array}$ & Pain (3) & Vision (2) & $\begin{array}{l}\text { Fatigue } \\
\text { (3) }\end{array}$ \\
\hline $\begin{array}{l}\text { Mean } \pm \text { SD } \\
95 \% \mathrm{Cl} \text { of the mean }\end{array}$ & $\begin{array}{l}71 \pm 20 \\
63-80\end{array}$ & $\begin{array}{l}76 \pm 25 \\
66-86\end{array}$ & $\begin{array}{l}78 \pm 23 \\
68-87\end{array}$ & $\begin{array}{l}80 \pm 16 \\
73-86\end{array}$ & $\begin{array}{l}80 \pm 18 \\
72-87\end{array}$ & $\begin{array}{l}71 \pm 24 \\
62-81\end{array}$ & $\begin{array}{l}88 \pm 13 \\
83-94\end{array}$ & $\begin{array}{l}81 \pm 16 \\
74-88\end{array}$ & $\begin{array}{l}70 \pm 28 \\
59-82\end{array}$ & $\begin{array}{l}86 \pm 21 \\
77-95\end{array}$ & $\begin{array}{l}80 \pm 25 \\
70-90\end{array}$ \\
\hline $\begin{array}{l}\text { Age } \\
\text { p-value }\end{array}$ & $\begin{array}{l}-0.07035 \\
0.7383\end{array}$ & $\begin{array}{r}-0.4934 \\
\mathbf{0 . 0 1 2 2}\end{array}$ & $\begin{array}{r}-0.3692 \\
0.0693\end{array}$ & $\begin{array}{r}-0.3874 \\
0.0557\end{array}$ & $\begin{array}{l}-0.322 \\
0.1165\end{array}$ & $\begin{array}{r}-0.3451 \\
0.0911\end{array}$ & $\begin{array}{l}0.07588 \\
0.7185\end{array}$ & $\begin{array}{r}-0.3089 \\
0.1330\end{array}$ & $\begin{array}{r}-0.2038 \\
0.3284\end{array}$ & $\begin{array}{r}-0.2573 \\
0.2211\end{array}$ & $\begin{array}{r}-0.3215 \\
0.1171\end{array}$ \\
\hline $\begin{array}{l}\text { Gender } \\
\text { Female: } \\
\text { Mean } \pm \text { SEM } \\
\text { p-value }\end{array}$ & $\begin{array}{l}72 \pm 7.9 \\
71 \pm 4.6 \\
0.8897\end{array}$ & $\begin{array}{l}69 \pm 8.3 \\
81 \pm 5.9 \\
0.2407\end{array}$ & $\begin{array}{l}67 \pm 8.5 \\
85 \pm 4.4 \\
0.0483\end{array}$ & $\begin{array}{l}83 \pm 3.0 \\
78 \pm 5.0 \\
0.4770\end{array}$ & $\begin{array}{l}78 \pm 6.7 \\
81 \pm 4.2 \\
0.6350\end{array}$ & $\begin{array}{l}62 \pm 8.0 \\
78 \pm 5.5 \\
0.1152 \\
\end{array}$ & $\begin{array}{l}94.2 \pm 2.1 \\
85 \pm 3.7 \\
0.1233 \\
\end{array}$ & $\begin{array}{l}78 \pm 6.8 \\
83 \pm 3.1 \\
0.4460\end{array}$ & $\begin{array}{l}73 \pm 7.9 \\
69 \pm 8.1 \\
0.7449\end{array}$ & $\begin{array}{l}85 \pm 5.8 \\
87 \pm 6.1 \\
0.5495 \\
\end{array}$ & $\begin{array}{l}63 \pm 9.8 \\
91 \pm 2.9 \\
\mathbf{0 . 0 0 8 1}\end{array}$ \\
\hline $\begin{array}{l}\text { HIV status } \\
\text { HIV NR: Mean } \pm \text { SEM } \\
\text { HIV R: Mean } \pm \text { SEM } \\
\text { p-value }\end{array}$ & $\begin{array}{l}72 \pm 4.5 \\
76 \pm 8.6 \\
0.6439\end{array}$ & $\begin{array}{c}76 \pm 6.5 \\
86 \pm 5.3 \\
0.3285\end{array}$ & $\begin{array}{l}79 \pm 5.2 \\
78 \pm 8.2 \\
0.9128\end{array}$ & $\begin{array}{l}79 \pm 4.3 \\
84 \pm 4.4 \\
0.5448\end{array}$ & $\begin{array}{l}83 \pm 4.0 \\
76 \pm 7.4 \\
0.3610\end{array}$ & $\begin{array}{l}69 \pm 5.5 \\
79 \pm \\
11.0 \\
0.3761\end{array}$ & $\begin{array}{l}88 \pm 3.2 \\
90 \pm 5.3 \\
0.6787\end{array}$ & $\begin{array}{l}82 \pm 4.1 \\
83 \pm 6.3 \\
0.8781\end{array}$ & $\begin{array}{l}65 \pm 7.7 \\
83 \pm 5.8 \\
0.1568\end{array}$ & $\begin{array}{l}83 \pm 6.3 \\
90 \pm 5.0 \\
0.7892\end{array}$ & $\begin{array}{c}82 \pm 5.0 \\
79 \pm 12.0 \\
0.8287\end{array}$ \\
\hline $\begin{array}{l}\text { mNIHSS } \\
\text { p-value }\end{array}$ & $\begin{array}{l}0.2534 \\
0.2217 \\
\end{array}$ & $\begin{array}{r}-0.3473 \\
0.0889 \\
\end{array}$ & $\begin{array}{r}-0.0314 \\
0.8817 \\
\end{array}$ & $\begin{array}{l}0.1303 \\
0.5349 \\
\end{array}$ & $\begin{array}{r}-0.0929 \\
0.6584 \\
\end{array}$ & $\begin{array}{l}0.1093 \\
0.6031 \\
\end{array}$ & $\begin{array}{l}0.2022 \\
0.3323 \\
\end{array}$ & $\begin{array}{l}0.1138 \\
0.5880 \\
\end{array}$ & $\begin{array}{l}0.1719 \\
0.4112 \\
\end{array}$ & $\begin{array}{l}0.0453 \\
0.8299 \\
\end{array}$ & $\begin{array}{r}-0.2536 \\
0.2212 \\
\end{array}$ \\
\hline $\begin{array}{l}\text { mRS at } 6 \text { months } \\
\text { p-value }\end{array}$ & $\begin{array}{r}-0.1552 \\
0.4589\end{array}$ & $\begin{array}{r}-0.5789 \\
\mathbf{0 . 0 0 2 4}\end{array}$ & $\begin{array}{l}-0.07347 \\
0.7271\end{array}$ & $\begin{array}{r}-0.3473 \\
0.0889\end{array}$ & $\begin{array}{c}-0.2702 \\
01915\end{array}$ & $\begin{array}{c}-0.0629 \\
0.7652\end{array}$ & $\begin{array}{l}0.0287 \\
0.8917\end{array}$ & $\begin{array}{r}-0.4328 \\
\mathbf{0 . 0 3 0 7}\end{array}$ & $\begin{array}{r}-0.2142 \\
0.3038\end{array}$ & $\begin{array}{r}-0.1762 \\
0.3995\end{array}$ & $\begin{array}{r}-0.2623 \\
0.2053\end{array}$ \\
\hline
\end{tabular}

NEWSQOL = Newcastle Stroke-specific Quality of Life Measure, ADL = Activities of daily living, SD= Standard deviation, Cl=Confidence interval, SEM=

Standard error of the mean, HIV NR= HIV nonreactive, HIV R = HIV reactive, mNIHSS = modified National Institution of Health Stroke Scale on admission, $\mathrm{mRS}=$ modified Rankin Scale score at 6 months;

Values in the 'Age', 'mNIHSS', and 'mRS at 6 months' rows are Pearson's $r$ values, which represent the magnitude of linear correlation between the variable labelled in a respective row and the NEWSQOL domains; $r$ values can range from -1 to +1 , where -1 is total negative correlation, 0 is no correlation, and +1 total positive correlation.

to move from the urban to the rural setting, where they have more relatives and available caregiving assistance. One-fifth of our study sample moved, following a stroke, from an urban environment to the countryside, where they often received better psychosocial support in a Malawian sociocultural context. This was one challenge for our study: with our limited time and funds, many patients were only reachable by phone.

Stroke patients in Malawi, as in other resource-poor countries, are, on average, younger than those in high-income countries. Older age was related to a poorer QOL in the ADL/physical function domain. Moreover, increased age was related to a more severe stroke and poorer recovery, which may explain the low ADL and physical function scores ${ }^{16}$. Elsewhere, findings related to age have been somewhat inconsistent; in one study older age was related to a higher socioeconomic position, but it did not predict overall QOL directly ${ }^{28}$. In other studies younger patients have had better post-stroke $\mathrm{QOL}^{3,12,22}$.

In our study, more than one-third of the surviving patients returned to their previous employment. According to the few who were interviewed by NEWSQOL, returning to their occupation did not significantly affect any domains of their QOL. In other studies, returning to work was related to a moderate life satisfaction boost when compared to those without employment ${ }^{5,21}$. Some of the stroke patients who continued working were surprisingly old in our study. This reflects the pressure on many elder Malawians to continue working to support their families.

No consensus exists about which QOL tool to use when evaluating post-stroke patients. Differences in the QOL measure, differences in the definition of QOL, and different criteria for study populations explain the large variety of results, which generates difficulties when trying to compare the results of different studies. We chose this stroke-specific questionnaire because of its flexibility-making it possible to evaluate illiterate patients as well as patients who do not have household responsibilities.

This is, as far as we know, the first time NEWSQOL has been used in Africa. It has recently been used in Europe in two countries: Luxembourg ${ }^{4,5}$, and comparing urban Luxembourg to rural Portugal ${ }^{21}$. These studies surveyed the QOL of patients and their caretakers two years after a stroke. QOL scores were lower in the Portuguese patients, whose rural setting is more comparable to the Malawian setting. The Portuguese subjects' QOL was more impaired in the domains of feelings (47.6 \pm 31.1 ), emotion (37.6 \pm 23.3$)$, and sleep $(57.8 \pm 28.7)$. Among our study participants, the domains that produced the lowest QOL scores also included feelings (71 \pm 20$)$ and sleep $(71 \pm 24)$, as well as the domain of pain $(70 \pm 28)$. Sleep was also one of the three lowest ranking QOL domains in Luxembourg (73.0 \pm 24.2.). Attention should be given to these domains when taking care of stroke patients. Sleep disturbances, in particular, are often linked to depression. Within each domain our participants generally rated their QOL better than their European counterparts, although such comparisons should be made with caution. Possible explanations include cultural differences between study populations or the selection bias in our study.

The limitations in this study are many. Future studies should consider training research staff in order to include more patients with dysphasia (on the milder end of the spectrum, at least) and those difficult to reach for appointment. The interviewed patients had milder index strokes and better functional outcomes, and we assume this surely affected the results in all domains. The number of interviews was small, which prevents a more detailed and robust statistical analysis, including multivariable analysis. NEWSQOL was validated in a Caucasian population but not for use in Sub-Saharan Africa. Some cultural and societal factors might affect the 
interpretations of the questions. Back-translation of the NEWSQOL tool may have improved the validity of our study.

\section{Conclusion}

To our knowledge, this is the first attempt to evaluate poststroke QOL in Malawi, and despite the limitations listed above, the results give us guidance for further research in this important field. This selected stroke population considered their quality of life high despite the losses caused by acute stroke. An individual stroke patient's subjective wellbeing can be influenced by cultural and geographical factors. Better management of rehabilitation and mobility, pain, and depression, especially in women with stroke, would help us to improve the QOL of stroke patients. In this study, HIV infection did not affect QOL.

\section{Acknowledgements}

We would like to acknowledge Maire Taponen Foundation for funding the project, Dr. Theresa Allain for the help with editing and for the statistical work, Mr. Tim Connell for language editing, and the medical staff and students at QECH for their help during the study period.

\section{References}

1. Fuhrer MJ. Subjectifying quality of life as a medical rehabilitation outcome. Disabil Rehabil 2000 Jul 20; 22(11): 481-9.

2. Jonkman EJ, de Weerd AW, Vrijens NL. Quality of life after a first ischemic stroke. long-term developments and correlations with changes in neurological deficit, mood and cognitive impairment. Acta Neurol Scand 1998 Sep; 98(3): 169-75.

3. Sturm JW, Donnan GA, Dewey HM, et al. Quality of life after stroke: The northeast Melbourne stroke incidence study (NEMESIS). Stroke 2004 Oct; 35(10): 2340-5.

4. Baumann M, Couffignal S, Le Bihan E, Chau N. Life satisfaction two-years after stroke onset: The effects of gender, sex occupational status, memory function and quality of life among stroke patients (Newsqol) and their family caregivers (Whoqol-bref) in Luxembourg. BMC Neurol 2012; 12: 105.

5. Baumann M, Lurbe K, Leandro ME, Chau N. Life satisfaction of twoyear post-stroke survivors: Effects of socio-economic factors, motor impairment, Newcastle stroke-specific quality of life measure and world health organization quality of life: Bref of informal caregivers in Luxembourg and a rural area in Portugal. Cerebrovasc Dis 2012; 33(3): 219-30

6. Ahlsio B, Britton M, Murray V, Theorell T. Disablement and quality of life after stroke. Stroke 1984 Sep-Oct; 15(5): 886-90.

7. Tang WK, Lu JY, Chen YK, Mok VC, Ungvari GS, Wong KS. Is fatigue associated with short-term health-related quality of life in stroke? Arch Phys Med Rehabil 2010 Oct; 91(10): 1511-5.

8. Carod-Artal FJ, Trizotto DS, Coral LF, Moreira CM. Determinants of quality of life in Brazilian stroke survivors. J Neurol Sci 2009 Sep 15 ; 284(1-2): 63-8.

9. Greeff M, Uys LR, Wantland D, et al. Perceived HIV stigma and life satisfaction among persons living with HIV infection in five african countries: A longitudinal study. Int J Nurs Stud 2010; 47(4): 475-486.

10. Fan AP, Kuo HC, Kao DY, Morisky DE, Chen YM. Quality of life and needs assessment on people living with HIV and AIDS in Malawi. AIDS Care. 2011; 23(3): 287-302.

11. Howitt SC, Jones MP, Jusabani A, et al. A cross-sectional study of quality of life in incident stroke survivors in rural northern Tanzania. J Neurol 2011 Aug; 258(8): 1422-30.
12. Muli G, Rhoda A. Quality of life amongst young adults with stroke living in Kenya. Afr Health Sci. 2013;13(3):632-638.

13. Owolabi MO. Determinants of health-related quality of life in Nigerian stroke survivors. Trans R Soc Trop Med Hyg 2008 Dec; 102(12): 1219-25.

14. Owolabi MO. Impact of stroke on health-related quality of life in diverse cultures: The Berlin-Ibadan multicenter international study. Health Qual Life Outcomes 2011; 9: 81.

15. Abubakar SA, Isezuo SA. Health related quality of life of stroke survivors: Experience of a stroke unit. Int J Biomed Sci 2012 Sep; 8(3): 183-7.

16. Heikinheimo T, Chimbayo D, Kumwenda JJ, Kampondeni S, Allain TJ. Stroke outcomes in Malawi, a country with high prevalence of HIV: A prospective follow-up study. PLoS One 2012; 7(3): e33765.

17. Bamford J, Sandercock P, Dennis M, Burn J, Warlow C. Classification and natural history of clinically identifiable subtypes of cerebral infarction. Lancet 1991 Jun 22; 337(8756): 1521-6.

18. Brott T, Adams HP,Jr, Olinger CP, et al. Measurements of acute cerebral infarction: A clinical examination scale. Stroke 1989 Jul; 20(7): 864-70.

19. Bonita R, Beaglehole R. Recovery of motor function after stroke. Stroke 1988 Dec; 19(12): 1497-500.

20. Buck D, Jacoby A, Massey A, Steen N, Sharma A, Ford GA. Development and validation of NEWSQOL, the Newcastle strokespecific quality of life measure. Cerebrovasc Dis 2004; 17(2-3): 143-52.

21. Baumann M, Le Bihan E, Chau K, Chau N. Associations between quality of life and socioeconomic factors, functional impairments and dissatisfaction with received information and home-care services among survivors living at home two years after stroke onset. BMC Neurol 2014 Apr 28; 14: 92,2377-14-92.

22. Kauhanen ML, Korpelainen JT, Hiltunen P, Nieminen P, Sotaniemi KA, Myllyla VV. Domains and determinants of quality of life after stroke caused by brain infarction. Arch Phys Med Rehabil 2000 Dec; 81(12): 1541-6.

23. Gargano JW, Reeves MJ, Paul Coverdell National Acute Stroke Registry Michigan Prototype Investigators. Sex differences in stroke recovery and stroke-specific quality of life: Results from a statewide stroke registry. Stroke 2007 Sep; 38(9): 2541-8.

24. Bushnell CD, Reeves MJ, Zhao X, et al. Sex differences in quality of life after ischemic stroke. Neurology 2014 Mar 18; 82(11): 922-31.

25. United Nations Development Programme (UNDP) Human Development Index. [Internet] [cited 2013 10/23]. Available from: http://hdrstats.undp.org/en/countries/profiles/MWI.html.

26. Paolucci S, Bragoni M, Coiro P, et al. Is sex a prognostic factor in stroke rehabilitation? A matched comparison. Stroke 2006 Dec; 37(12): 2989-94.

27. de Lima ML, Santos JL, Sawada NO, de Lima LA. Quality of life of individuals with stroke and their caregivers in a city of Triangulo Mineiro. Rev Bras Epidemiol 2014 Apr-Jun; 17(2): 453-64.

28. King RB. Quality of life after stroke. Stroke 1996 Sep; 27(9): 146772. 